\title{
Enhancing the NICU language environment with a neonatal Cuddler program
}

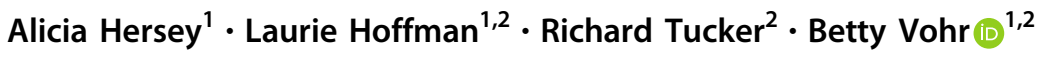

Received: 21 August 2020 / Revised: 11 December 2020 / Accepted: 1 March 2021 / Published online: 26 March 2021

(c) The Author(s), under exclusive licence to Springer Nature America, Inc. 2021

\begin{abstract}
Objective To compare effects of a language intervention on Cuddler and parent adult word counts (AWC), and to compare Cuddler versus parent and nurse-care times.

Design Prospective pilot cohort intervention study. Twelve Cuddler-low-visit ( $\leq 2 /$ week) infant pairs and 17 high-visit ( $\geq 3$ /week) parent-infant pairs were enrolled. Each had a 16-hour baseline recording (R1) followed by a language curriculum with linguistic feedback and an outcome recording (R2) 1 week later. Bivariate group analyses and longitudinal negative binomial regressions were run.

Results After the intervention, there were non-significant increases in AWC/h for Cuddlers and high-visit parents. Cuddler AWCs were similar to high-visit parents and significantly higher than nurse-care times on both recordings. Within the lowvisit group, hourly AWCs were higher when Cuddlers were present versus absent $(\mathrm{R} 1=1779$ versus $552, \mathrm{R} 2=2530$ versus $534, p<0.0001$ ).

Conclusions NICU language environments are different for low-visit and high-visit infants and Cuddlers can increase infant language exposure in the NICU.
\end{abstract}

\section{Introduction}

Maternal voice is one of the most important stimuli for the developing fetus in utero [1], and previous research has shown that fetuses develop recognition for maternal voice by 34 weeks' gestation [2]. Infants born prematurely are deprived of the continuous exposure to maternal voice in the womb and may be exposed to considerably less language in the neonatal intensive care unit (NICU) $[3,4]$ that can contribute to developmental delays later in childhood [5-7]. Studies have shown deprivation of maternal voice shortly after birth affects both auditory brain development and childhood language [8-10]. Both the quality and quantity of language exposure affect language acquisition and outcomes [3, 11-14]. Hart and Risley first demonstrated the importance of the quantity of language exposure in early language development. Studies within our

Betty Vohr

bvohr@wihri.org

1 Department of Pediatrics, Brown University, Providence, RI, USA

2 Women \& Infants Hospital of Rhode Island, Providence, RI, USA
NICU have confirmed that exposure to increased number of adult words in the NICU improves cognitive and language scores at 18 months. These authors also identified that parental speech, over non-parental speech, has stronger influences on child vocalizations and conversations, which have been linked to development outcomes [3]. The impacts of the quality of speech were supported by Ramirez-Esparza et al. who identified that factors such as "parentese speech" and one-on-one interactions are positively correlated with concurrent speech and future word production [13, 14]. High maternal involvement improves short- and long-term outcomes including provision of breast milk, improved weight gain, decreased stress, and improved development at 18-24 months [15-17]. Active maternal involvement is encouraged by staff in our single-family room NICU. Increased duration of parental presence including any holding, or skin-to-skin in the NICU has been associated with improved neurobehavioral and motor outcomes in infants $\leq 32$ weeks [18]. However, there are often barriers preventing parental visiting such as transportation, childcare support, inadequate maternity leave, or limitations due to state custody of infant [19].

The Women and Infants Hospital Cuddler program was initiated in August 2013 to address limited parental 
Fig. 1 Cuddler study protocol outline. Shown are the study group sample size numbers $(\mathrm{N})$ at time of enrollment, time of recording 1 , and time of recording 2 . The language intervention occurred after recording 1 .

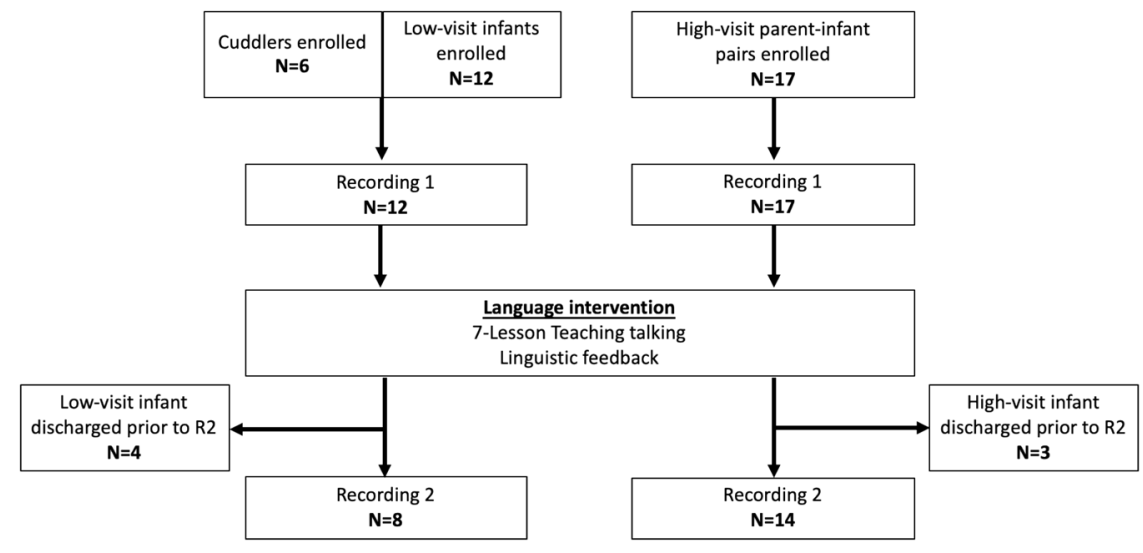

visitation to a subset of high-risk infants. Infants are eligible if parents visit $\leq 2$ times per week. The program was designed to provide infants with direct human contact (holding and cuddling) for a 1-h session once or twice a week. Cuddler programs have been shown to be beneficial for both immediate health status (stabilized vital signs, weight gain, and feeding) as well as later development [20]. Prior to this study, our Cuddlers did not have specific education on techniques to enhance the infant's language environment.

The language environment analysis (LENA) digital language processor was designed as a measurement tool to gain insight into the natural language environment of children [21]. LENA has previously been used to measure the language environment in our NICU in a prospective cohort of extremely preterm infants. Exposure to parental talk, compared to other adults, was a significant predictor of infant vocalizations at 32 weeks and conversational turns between infant and parent at 32 and 36 weeks [3]. Quantitative linguistic feedback to parents on LENA recording word and vocalization counts to demonstrate opportunities for enhanced language interaction has been shown to result in significant and sustained increases in adult speech and conversations [22]. A similar curriculum created by the study authors and tailored for adolescent mothers at our institution demonstrated significant increases in infant vocalizations and conversations [23].

The Cuddler program provided an opportunity to utilize the LENA device to explore and compare the language environments of two groups of infants, those with low parental visitation (low-visit) and those with high parental visitation (high-visit). The primary objective was to evaluate the effect of a language intervention curriculum in conjunction with the LENA linguistic feedback given to Cuddler volunteers assigned to low-visit infants and to high-visit parent-infant pairs on levels of adult words, conversational turns, and infant vocalizations. The secondary objectives were to compare the language counts during low-visit Cuddler time to high-visit parent-care time and nurse-care time, and to compare times when Cuddler was present versus absent within the low-visit group.

We hypothesized that after the intervention, LENA counts would increase for both groups and be similar between Cuddler time and high-visit parent-care times. Second, LENA counts would be higher during Cuddler time than nurse-care time.

\section{Methods}

\section{Cohort}

This prospective cohort pilot study of infants in the NICU was conducted in Women \& Infants Hospital (Providence, RI) single-family room NICU between 07 August 2014 and 15 October 2016. IRB approval was obtained. Outline of the study protocol is shown in Fig. 1 Informed consent (phone or written from low-visit parents; written from Cuddler and high-visit parents) was obtained. Enrolled infants were expected to be in the NICU for at least 2 additional weeks after enrollment in order to complete the study protocol. Low-visit infants were already participating in the Cuddler program because their parents visited $\leq 2$ times per week. A high-visit parent-infant comparison group was defined as parental visitation $\geq 3$ times per week and were enrolled based on parent availability. Each Cuddler had a set weekday schedule and visited infants once per week for 1-2 hours. Once enrolled, a Cuddler was paired with a low-visit infant whom they were instructed to cuddle once weekly for 2 consecutive weeks, after which they could be paired with a second low-visit infant.

\section{Language interventions}

The LENA word processing system captures every utterance exchanged between parents/caregivers and infant and are reported as adult word count (AWC), conversational turns (conversations), and child vocalizations (vocalizations). An 
AWC is an estimate of the number of words spoken near the infant. A conversation is defined as a vocalization followed by an adult response within 5 seconds or vice versa. Each reciprocal exchange is counted as one conversation. A vocalization is comprised of infant speech including pre-speech communicative sounds such as babbles, squeals, and raspberries and excludes cries or vegetative sounds [21]. Reliability testing has demonstrated that AWC, conversations, and vocalizations have strong correlations to human transcription counts $(r=0.95$, 0.82, 0.83, respectively) [24, 25]. Each Cuddler-low-visit infant pair and high-visit parent-infant pair had two recordings, 1 week apart. After Recording 1 (R1), one of two study personnel, for whom inter-rater reliability on administration of the language curriculum was established, provided the Teaching Talking Curriculum with the Cuddler or high-visit parent. Teaching Talking is a language curriculum designed for this and another concurrent study and consisted of seven lessons that incorporate methods for early language enrichment [22, 23, 26-28]. The seven lessons include What's My Corrected Age?, Watch Me Learn Language, Talking to Babies, Reading Aloud, Sing-A-long, Copying First Sounds, and Playing Games. These brief lessons took $\sim 1 \mathrm{~h}$ to review with the Cuddler or parent and the primary objective was to teach strategies to increase the amount and quality of language around infants. The Cuddlers and high-visit parents also received linguistic feedback on all recordings, which included a review of the summary LENA printout of their recording demonstrating times of high/low AWC, reciprocal conversation, child vocalizations, and opportunities to increase AWC. Recording 2 (R2) was performed 1 week later, when Cuddlers and high-visit parents were scheduled to visit. Because of the limited number of Cuddlers at our site, Cuddlers were paired with additional low-visit infants as available.

\section{Data collection}

Maternal and infant characteristics, morbidities, and demographic data were collected from the electronic medical record. An activity log to designate the predominant activity occurring each hour (feeding, care time, parent/ Cuddler visiting, or infant sleeping) was filled out by the infant's nurse or parent during each recording. Using the logs, recordings were coded into hourly "activities" based on the activity that occurred for the majority of each hour. NICU care times occur every 3-4 hours, can involve both parent and/or nurses and include activities such as kangaroo or skin-to-skin time, feeding, diaper changes, and vital signs. "Parent-care time" was defined as a care time when a parent was present. "Nurse-care time" was defined as a care time when a parent was not present. "Cuddler time" was defined as time the Cuddler was with the infant and typically included a 1-2-hour period with the Cuddler engaging the infant through holding, singing, reading, or talking.
Activity logs were cross-referenced with electronic nursing documentation in cases where logs were incomplete or if there was ambiguity in one predominant activity.

LENA was used to record 16 hour of real-time audio data that was downloaded and processed by LENA language environment software V3.1.0. The automated printout was used for linguistic feedback to the Cuddler and high-visit parents of each recording giving positive reinforcement of elevated counts and demonstrating opportunities to increase counts.

\section{Statistical analyses}

Maternal and infant characteristics were compared by group using $t$-tests or Wilcoxon tests for continuous variables and chi-square tests for categorical variables. Non-normally distributed and highly dispersed hourly counts (AWC, conversations, vocalizations) were compared for each event type by group, adjusted for post-conception age at each recording time, using negative binomial regression. The primary outcome was the Cuddler and high-visit parent group LENA AWC, conversations, and vocalizations on $\mathrm{R} 2$. Longitudinal negative binomial regression using generalized estimating equations to adjust for repeated measures, with an event-by-time interaction term for each group was used to analyze change between recordings and the effect of the language intervention. Effect sizes for change were expressed as rate ratios. Analyses were run for all enrolled. Although it was not anticipated that low-visit parents would be present during a recording, six unique low-visit mothers were present during either R1 or R2, two of which were present with recording data for both R1 and $\mathrm{R} 2$. To analyze the difference in hourly counts with Cuddlers present versus absent within the low-visit group, hourly counts for all non-Cuddler time were aggregated and compared to mean hourly Cuddler counts. All statistical analyses were conducted by using SAS 9.1 (SAS Institute, Inc., Cary, NC).

\section{Results}

Convenience samples of 12 low-visit infants participating in the Cuddler program, including two sets of twins, and 17 high-visit infants, including one set of twins, were enrolled and completed R1. Table 1 shows the maternal and infant demographic data for the low-visit and high-visit groups. There were no significant group differences in maternal age, public insurance, race, prenatal care, or mode of delivery. A greater proportion of primigravida mothers was in the highversus low-visit group $(56 \%$ versus $10 \%, p=0.04)$. Although infants in the low-visit group were hospitalized for a significantly longer duration, post-menstrual ages at 
Table 1 Maternal and infant characteristics.

\begin{tabular}{|c|c|c|c|}
\hline & Low-visit & High-visit & $p$ \\
\hline Maternal characteristics & $N=10$ & $N=16$ & \\
\hline Maternal age, years $\mathrm{M} \pm \mathrm{SD}$ & $26.6 \pm 5$ & $29.9 \pm 5$ & 0.09 \\
\hline Gravida, $N(\%)$ & & & 0.04 \\
\hline 1 & $1(10)$ & $9(56)$ & \\
\hline 2 & $6(60)$ & $2(13)$ & \\
\hline$\geq 3$ & $3(30)$ & $5(31)$ & \\
\hline Public insurance, $N(\%)$ & $7(70)$ & $6(38)$ & 0.24 \\
\hline \multicolumn{4}{|l|}{ Race, $N(\%)$} \\
\hline White & $6(60)$ & $12(75)$ & 0.72 \\
\hline Black & $1(10)$ & $2(13)$ & \\
\hline Hispanic & $1(10)$ & $1(6)$ & \\
\hline Other & $2(20)$ & $1(6)$ & \\
\hline Prenatal care, $N(\%)$ & $8(80)$ & $15 / 15(100)$ & 0.07 \\
\hline Vaginal delivery, $N(\%)$ & $4(40)$ & $7(44)$ & 0.64 \\
\hline Infant characteristics & $N=\mathbf{1 2}$ & $N=\mathbf{1 7}$ & \\
\hline Twins & 2 sets & 1 set & \\
\hline Gestational age, weeks $\mathrm{M} \pm \mathrm{SD}$ & $28.5 \pm 5.2$ & $31.2 \pm 4.6$ & 0.14 \\
\hline Birth weight, grams $\mathrm{M} \pm \mathrm{SD}$ & $1210 \pm 833$ & $1796 \pm 1209$ & 0.16 \\
\hline Male sex, $N(\%)$ & $7(58)$ & $12(71)$ & 0.49 \\
\hline RDS, $N(\%)$ & $8(67)$ & $10(59)$ & 0.67 \\
\hline $\mathrm{BPD}, N(\%)$ & $4(33)$ & $4(24)$ & 0.56 \\
\hline $\begin{array}{l}\text { Days in hospital, } \mathrm{M} \pm \mathrm{SD} \\
\text { (median) }\end{array}$ & $94 \pm 45(93)$ & $63 \pm 32(54)$ & 0.049 \\
\hline $\begin{array}{l}\text { Days on ventilator, } \mathrm{M} \pm \mathrm{SD} \\
\text { (median) }\end{array}$ & $25.6 \pm 37$ & $\begin{array}{l}9.3 \pm \\
18(1.0)\end{array}$ & 0.17 \\
\hline Recording 1 & $N=12$ & $N=\mathbf{1 7}$ & \\
\hline Total hours of recording analyzed & 175 & 261 & \\
\hline PMA, weeks, $\mathrm{M} \pm \mathrm{SD}$ & $38.1 \pm 3.3$ & $37.3 \pm 3.8$ & 0.66 \\
\hline Recording 2 & $N=\mathbf{8}$ & $N=14$ & \\
\hline Total hours of recording analyzed & 110 & 203 & \\
\hline PMA, weeks, $\mathrm{M} \pm \mathrm{SD}$ & $40.7 \pm 4.1$ & $38.4 \pm 4.2$ & 0.20 \\
\hline
\end{tabular}

$R D S$ respiratory distress syndrome, $B P D$ bronchopulmonary dysplasia, $P M A$ post-menstrual age.

R1 and R2 in both groups were similar. Due to scheduling issues or early discharge, $8 / 12(67 \%)$ dyads in the low-visit group and $14 / 17(82 \%)$ in the high-visit group completed the protocol and had both R1 and R2 (Fig. 1).

Table 2 compares LENA counts on R2 versus R1 during Cuddler time, high-visit parent-care time and low-visit parent-care time (nonintervention comparison) for infants who had both recordings. While there were no significant increases in LENA counts for any of the groups, AWC count increased between R1 and R2 for both Cuddler time (rate ratio $=1.33,95 \% \mathrm{CI}=0.68-2.59, p=0.41)$ and highvisit parent-care time (rate ratio $=1.39,95 \% \mathrm{CI}=$ $0.99-1.94, p=0.06$ ) but decreased for low-visit parent-care time (rate ratio $0.69,95 \% \mathrm{CI}=0.29-1.63, p=0.40$ ). There were similar trends for conversations and vocalizations.
Table 3 shows LENA counts during Cuddler time compared to high-visit group parent-care time and nurse-care time for all recordings obtained. AWC was similar during Cuddler time and high-visit parent-care time on R1 and R2. Cuddler AWC was significantly higher than during nursecare time (1779 versus $447, p=0.03$ ) on $\mathrm{R} 1$, and group differences increased in $\mathrm{R} 2$ following the language intervention with the Cuddlers (2530 versus $349, p=0.0001$ ). Conversations were also higher during Cuddler time than nurse-care time on both R1 (7.4 versus $2.4, p=0.008$ ) and R2 (13.7 versus 3.2, $p=0.003)$. Vocalizations were nonsignificantly higher during Cuddler time than nurse-care time on both recordings.

Table 4 compares LENA counts during times when the Cuddler was present compared to absent for low-visit infants during R1 and R2. Hourly AWC was significantly higher with Cuddlers present on R1 (1779 versus 552, $p<$ $0.0001)$ and $\mathrm{R} 2$ (2530 versus 534, $p<0.0001)$. On R2 after receiving the intervention, hourly conversation turns were also significantly higher with Cuddler present (present $=$ 13.7 versus absent $=4.7, p=0.005$ ). Vocalizations were similar on both recordings.

Table 5 (online) compares LENA counts during parent and nurse-care times for the low-visit group, excluding Cuddler time, versus the high-visit group on R1 and R2. Low-visit infant had less parent-care time (3-5\% of recordings) than high-visit infants (21-26\% of recordings). During parent-care time, low-visit and high-visit infants were exposed to similar hourly AWC on R1; however, postintervention, low-visit infants, whose parents had not received any intervention, were exposed to significantly lower hourly AWC during parent-care time than infants of high-visit parents (R2 995 versus 1887, $p=0.01$ ). During nursing care times, low-visit infants were exposed to higher AWC by nurses than high-visit infants $(\mathrm{R} 1=782$ versus $447, p=0.46$; $\mathrm{R} 2=894$ versus $349, p=0.02$ ). Similarly, during nurse-care time, low-visit infants had significantly more conversations $(\mathrm{R} 1=6.8$ versus $2.4, p=0.01$; $\mathrm{R} 2=$ 5.9 versus $3.2, p=0.25)$ and vocalizations $(\mathrm{R} 1=29.6$ versus $8.9, p=0.001 ; \mathrm{R} 2=26.1$ versus $13.4, p=0.29$ ) than high-visit infants.

\section{Discussion}

Prior research has demonstrated the importance of early language exposure in the short- and long-term development of normal speech and language processing [3, 11, 29-31]. This is the first study to analyze the effects of a LENA-based language curriculum on a Cuddler program for infants of lowvisit parents in comparison to high-visit parents. Prior to the current study, our Cuddlers did not have guidelines or a curriculum on how to enhance the language environment. Our 
Table 2 LENA counts and their rate ratios for Recording 2 versus Recording 1 for the 8 low-visit and 14 high-visit infants with both recordings.
Table 3 LENA counts for Cuddler time in the low-visit group compared to high-visit parent- and nurse-care time for Recordings 1 and 2.

\begin{tabular}{|c|c|c|c|c|}
\hline Event type & $\begin{array}{l}\text { Recording } 1 \\
\bar{x} \pm \mathrm{SD} \text { (median) }\end{array}$ & $\begin{array}{l}\text { Recording } 2 \\
\bar{x} \pm \mathrm{SD} \text { (median) }\end{array}$ & $\begin{array}{l}\text { Rate ratio } \\
(\mathrm{R} 2: \mathrm{R} 1)(95 \% \mathrm{CI})\end{array}$ & $p$ \\
\hline High-visit hours of recording & $\begin{array}{l}203 \text { hours } \\
\text { Infant } N=14\end{array}$ & & & \\
\hline \multicolumn{5}{|l|}{ High-visit parent-care time } \\
\hline Hours, $N(\%)$ & $54 / 203(27)$ & $42 / 203(21)$ & & \\
\hline AWC & $1644 \pm 1852(1002)$ & $1888 \pm 1882(1368)$ & $1.39(0.99-1.94)$ & 0.06 \\
\hline Conversations & $10 \pm 10(7)$ & $13 \pm 18(7)$ & $1.33(0.92-1.92)$ & 0.13 \\
\hline Vocalizations & $24 \pm 23$ & $26 \pm 32(16)$ & $1.20(0.85-1.69)$ & 0.3 \\
\hline Low-visit hours of recording & $\begin{array}{l}110 \text { hours } \\
\text { Infant } N=8\end{array}$ & & & \\
\hline \multicolumn{5}{|l|}{ Cuddler time } \\
\hline Hours, $N(\%)$ & $17 / 110(15)$ & $13 / 110(12)$ & & \\
\hline AWC & $1609 \pm 1786(894)$ & $2530 \pm 2025(1956)$ & $1.33(0.68-2.59)$ & 0.41 \\
\hline Conversations & $7 \pm 7(5)$ & $13.7 \pm 13(8.0)$ & $1.49(0.64-3.45)$ & 0.35 \\
\hline Vocalizations & $12 \pm 12(11)$ & $24.5 \pm 22(11.0)$ & $1.38(0.57-3.33)$ & 0.47 \\
\hline \multicolumn{5}{|l|}{ Low-visit parent-care time } \\
\hline Hours, $N(\%)$ & $4 / 110(4)$ & $4 / 110(4)$ & & \\
\hline AWC & $1649 \pm 861(1496)$ & $995 \pm 1055(763)$ & $0.69(0.29-1.63)$ & 0.4 \\
\hline Conversations & $13 \pm 1014)$ & $5.8 \pm 8.6(0)$ & $0.39(0.10-1.55)$ & 0.18 \\
\hline Vocalizations & $40 \pm 36(35)$ & $13.4 \pm 16$ & $0.29(0.07-1.10)$ & 0.07 \\
\hline
\end{tabular}

$A W C$ adult word count, Conversations conversational turns, Vocalizations child vocalizations.

\begin{tabular}{|c|c|c|c|c|c|}
\hline \multirow[b]{2}{*}{ Recording 1} & \multirow[t]{2}{*}{ Low-visit parent group } & \multicolumn{4}{|c|}{ High-visit parent group } \\
\hline & & & & & \\
\hline Infants, $N$ & 12 & 17 & & & \\
\hline Total hours & 175 & 261 & & & \\
\hline Care time & Cuddler & Parent & $p$ & Nurse & $p$ \\
\hline Hours, $N(\%)$ & $21(12)$ & $68(26)$ & & $35(13)$ & \\
\hline AWC & $1779 \pm 1738(1062)$ & $1680 \pm 1730(1214)$ & 0.84 & $447 \pm 1209(102)$ & 0.03 \\
\hline Conversations & $7.4 \pm 6.9(6.0)$ & $9.8 \pm 9.2(7.0)$ & 0.2 & $2.4 \pm 3.6(0)$ & 0.008 \\
\hline Vocalizations & $13.9 \pm 13(14)$ & $23.1 \pm 22(16)$ & 0.1 & $8.9 \pm 9.6(6.0)$ & 0.08 \\
\hline \multicolumn{6}{|l|}{ Recording 2} \\
\hline Infants, $N$ & 8 & 14 & & & \\
\hline Total hours & 110 & 203 & & & \\
\hline Care time & Cuddler & Parent & $p$ & Nurse & $p$ \\
\hline Hours, $N(\%)$ & $13(12)$ & $42(21)$ & & 35 (17) & \\
\hline AWC & $2530 \pm 2025(1956)$ & $1887 \pm 1882(1367)$ & 0.28 & $349 \pm 492(163)$ & 0.0001 \\
\hline Conversations & $13.7 \pm 13(8.0)$ & $12.9 \pm 18(6.5)$ & 0.41 & $3.2 \pm 5.6(1.0)$ & 0.003 \\
\hline Vocalizations & $24.5 \pm 22(11.0)$ & $26.3 \pm 33(15)$ & 0.79 & $13.4 \pm 21$ & 0.31 \\
\hline
\end{tabular}

$A W C$ adult word count, Conversations conversational turns, Vocalizations child vocalizations.

study findings provide support for our primary hypothesis that LENA counts would increase after an easy-to-administer language intervention with linguistic feedback. Rates of adult speech increased 1.33-1.39-fold, for both Cuddlers and highvisit parents. This is viewed in contrast to the counts for the small sample of two low-visit parents who were present during both R1 and R2 without any intervention, which decreased between the two recordings. In the Suskind et al. [26] LENA study, eight weekly home visits for 1-hour language education sessions showed significant and sustained differences in LENA counts. A similar curriculum for Cuddler and NICU parents may further strengthen the increases in speech measured by LENA and lead to sustained behavioral changes. 
Table 4 Hourly LENA counts on Recordings 1 and 2 in the presence versus absence of a Cuddler within low-visit group for all hours.

\begin{tabular}{|c|c|c|c|c|c|c|c|c|}
\hline Recording & Count & Cuddler present & Minimum & Maximum & Cuddler absent & Minimum & Maximum & $p$ \\
\hline & Hours, $N(\%)$ & $21(12)$ & & & $154(88)$ & & & \\
\hline R1 175 hours & AWC & $1779 \pm 1738$ & 83 & 6422 & $552 \pm 918$ & 0 & 5571 & $<0.0001$ \\
\hline \multirow[t]{3}{*}{$N=12$ infants } & Conversations & $7.4 \pm 6.9$ & 0 & 22 & $4.6 \pm 8.1$ & 0 & 41 & 0.18 \\
\hline & Vocalizations & $13.9 \pm 12.5$ & 0 & 45 & $20.9 \pm 30.2$ & 0 & 192 & 0.31 \\
\hline & Hours, $N(\%)$ & 13 (12) & & & $97(88)$ & & & \\
\hline R2 110 hours & AWC & $2530 \pm 2025$ & 799 & 8399 & $534 \pm 804$ & 0 & 4374 & $<0.0001$ \\
\hline \multirow[t]{2}{*}{$N=8$ infants } & Conversations & $13.7 \pm 12.7$ & 1 & 38 & $4.7 \pm 9.6$ & 0 & 43 & 0.005 \\
\hline & Vocalizations & $24.5 \pm 22.1$ & 2 & 63 & $26.5 \pm 44.5$ & 0 & 184 & 0.77 \\
\hline
\end{tabular}

R1 Recording 1, R2 Recording 2, AWC adult word count, Conversations conversational turns, Vocalizations child vocalizations.

Table 5 (Online): comparison of LENA counts by event for the low-visit group when the Cuddlers were not present and high-visit group during parentand nurse-care time.

\begin{tabular}{|c|c|c|c|c|c|c|}
\hline \multirow[t]{2}{*}{ Activity type } & \multicolumn{2}{|l|}{ Recording 1} & \multirow[t]{2}{*}{$p$} & \multicolumn{2}{|l|}{ Recording 2} & \multirow[t]{2}{*}{$p$} \\
\hline & $\begin{array}{l}\text { Low-visit } \\
\bar{x} \pm \text { SD (median) }\end{array}$ & $\begin{array}{l}\text { High-visit } \\
\bar{x} \pm \mathrm{SD} \text { (median) }\end{array}$ & & $\begin{array}{l}\text { Low-visit } \\
\bar{x} \pm \mathrm{SD} \text { (median) }\end{array}$ & $\begin{array}{l}\text { High-visit } \\
\bar{x} \pm \mathrm{SD} \text { (median) }\end{array}$ & \\
\hline Total hours of recording & 175 & 261 & & 110 & 203 & \\
\hline \multicolumn{7}{|l|}{ Parent-care time } \\
\hline Hours, $N(\%)$ & $6(3)$ & $68(26)$ & & $5(5)$ & $42(21)$ & \\
\hline AWC & $1427 \pm 753(1055)$ & $1681 \pm 1731(1215)$ & 0.14 & $995 \pm 1055(763)$ & $1887 \pm 1882$ & 0.01 \\
\hline Conversations & $10.3 \pm 10(8.5)$ & $9.8 \pm 9.2(7.0)$ & 0.98 & $5.8 \pm 8.6(0)$ & $12.9 \pm 18(6.5)$ & 0.17 \\
\hline Vocalizations & $34.3 \pm 29(31.0)$ & $23.1 \pm 22(16.5)$ & 0.29 & $13.4 \pm 16(4)$ & $26.3 \pm 33(15)$ & 0.35 \\
\hline \multicolumn{7}{|l|}{ Nurse-care time } \\
\hline Hours, $N(\%)$ & $53(30)$ & $35(13)$ & & $31(28)$ & $35(17)$ & \\
\hline AWC & $782 \pm 1051(330)$ & $447 \pm 1209(102)$ & 0.46 & $894 \pm 965(554)$ & $349 \pm 493(163)$ & 0.02 \\
\hline Conversations & $6.8 \pm 10(3.0)$ & $2.4 \pm 3.6(0)$ & 0.01 & $5.9 \pm 9.6(2.0)$ & $3.2 \pm 5.6(1.0)$ & 0.25 \\
\hline Vocalizations & $29.6 \pm 36(14.0)$ & $8.9 \pm 9.6(6.0)$ & 0.0001 & $26.1 \pm 44(12)$ & $13.4 \pm 21(4.0)$ & 0.29 \\
\hline
\end{tabular}

There were four low-visit parents visiting during Recording 1 for a total of $6 \mathrm{~h}$ and four visiting during Recording 2 for a total of $5 \mathrm{~h}$.

AWC adult word count, Conversations conversational turns, Vocalizations child vocalizations.
Second, we identified that Cuddler time for low-visit infants exposed them to a similar hourly AWC compared to high-visit infants and significantly more AWC than during high-visit nurse-care times. Prior studies have shown the importance of maternal involvement in the single-family room NICU [17, 32] and the association with improved outcomes [15-17]. However, single-family room NICUs may also have an adverse effect on language development due to limited parent visitation and decreased meaningful auditory sensory exposure [30, 31]. Cuddler time provides an opportunity to expose infants of low-visiting families to higher levels of adult contact and AWC. A simple language curriculum for Cuddlers may act as a surrogate for high-visit parents care times to mitigate some of the negative impact of single-family rooms when parents are not able to visit.

This study shows the contrast in language environments when Cuddlers are present and absent for low-visit infants. This difference was even more pronounced after Cuddlers received the language intervention. In addition, the Cuddler AWC on R2 was associated with significantly higher conversation turns, which are assumed to be interactive and have been reported to be associated with improved language and cognitive development [11,33]. This may be due to more meaningful interactions between the Cuddler and infant as was modeled in the intervention curriculum. This raises several practical and research questions. Should Cuddlers visit for longer than 1 hour or more frequently for infants of low-visit parents? Should Cuddlers visit any infant whose parents are not visiting? We did not expect to capture low-parent group visitation on our recordings. However, this provided the opportunity to compare the lowand high-visit parents. It was of interest that counts between the groups during parent-care time were similar at baseline, but after the language intervention, the high-visit group's AWC continued to increase whereas the low-visit group AWC decreased, demonstrating that low-visit parents could also benefit from a language curriculum. Another finding of interest was that nurses spoke almost twice as much to lowvisit infants during nurse-care times. We suspect that there is recognition by providers that low-visit infants would benefit from contact, and nurses empathetically respond by increasing their involvement. We believe that providers 
across a variety of disciplines (nursing, respiratory, physicians) would benefit from information about the benefits of a nurturing and language-rich environment for infants in the NICU and tools to help provide such an environment.

It has been reported that some healthcare providers may have conscious or unconscious biases based on race, socioeconomic status, state custody, or assumptions about parent's lack of desire or inability to visit their child that impact on their own behavior [34, 35]. However, at baseline, our low-visit parents had hourly word counts similar to high-visit parents for the short time they were present. As expected, low-visit infants had a lower percentage of time spent doing actual "parent"-care time. We suggest this is multifactorial. These parents may not feel as comfortable participating in their child's care as parents who visit regularly. Reasons parents may not visit are often real-life barriers and include other children at home, requirement to return to work or transportation issues, not just protective services restrictions. For example, we found that low-visit parents were more likely to be multiparous and childcare of other children may have contributed to difficulties visiting. Regardless of the reason, this study demonstrates the difference in language environments for infants whose parents visit frequently versus those whose parents can't or don't and provides an opportunity to enhance the language environment for them all.

This pilot study has several strengths including the implementation of an easy language intervention for Cuddlers and parents that we believe in a larger sample size would significantly increase language exposure to infants. This is the first study to analyze and compare the language environments of two groups of infants in a single-family room NICU, those whose parents visit frequently and those whose parents do not. This allowed several granular comparisons such as between Cuddlers and high-visit parentcare times, times with the Cuddler present versus absent for low-visit infants, and nursing care times between groups. In addition, although infants were enrolled in the Cuddler program based on low visitation, six unique low-visit parents were present during either R1 or R2. This became a strength for the study because it allowed us to analyze their counts and have a sense of the language environment during low-visit parent-care times and compare it to that of highvisit parents. This study identified a variety of opportunities for targeted interventions with both parents and staff to create a maximally language-rich environment for our NICU patients, many of whom are at high risk for language impairments based on prematurity or other morbidities.

Limitations of this study included a small sample size. As such, to maximize sample size, Cuddlers were paired as needed with more than one infant as available. Since R1 and $\mathrm{R} 2$ were based on the infant, a Cuddler may have received the curriculum and the linguistic feedback with a previous infant. The linguistic feedback of the R1 recording, however, is individualized and is felt to be an important motivator. Cuddlers continued to receive linguistic feedback after every recording. Second, although the hourly increments analyzed may not precisely coincide with Cuddler and parent visit times, this was addressed by a detailed log with cross-reference to nursing documentation and the hourly activity was labeled as the event that occurred during the majority of that time interval. Although the NICU language environment has been studied before in preterm infants, there is no normative dataset for this population. Furthermore, the algorithm for language processing does not discern adult speech that is child-directed, however, conversation turns are assumed to be interactive and a better surrogate for quality of language interactions than adult words.

In conclusion, this study validates the use of Cuddler programs for infants whose parents are not able to visit regularly. Our results suggest positive effects following a language intervention with linguistic feedback, for both Cuddler and high-visit parent-infant pairs. It supports that all families and healthcare providers may benefit from training in providing language-rich environments for infants in the NICU. Future studies are needed to further explore both the short- and long-term developmental benefits for infants.

\section{Table of contents summary}

After a NICU language intervention, Cuddlers had word counts and conversations similar to high-visit parents and significantly higher than nurse-care times.

\section{What is known on this subject}

- Although there are known benefits of mother-infant contact and an interactive language environment, there are barriers that prevent this valuable interaction for many infants cared for in the NICU.

- Many NICUs now have Cuddler programs to address infant sensory deprivation.

\section{What this study adds}

- Cuddlers provided with a language curriculum and feedback of their word counts while with an infant achieved hourly word counts similar to parents who visited frequently, and significantly improved the language environment of the infant with low parental visitation. 
Author contributions Alicia Hersey conceptualized and designed the study, performed the initial literature review, assisted in data collection, provided interpretation of the data, and drafted, reviewed and revised all the content in the manuscript. LH conceptualized and designed the study, supervised data collection, and critically reviewed the manuscript for intellectual content. BV contributed substantially to the study design, assisted in data collection, and critically reviewed the manuscript for intellectual content. RT contributed substantially to the manuscript design and data analyses as well as interpretation and critically reviewed the manuscript, particularly the statistical methods and integrity; and all authors approved the final manuscript as submitted and agree to be accountable for all aspects of the work.

\section{Compliance with ethical standards}

Conflict of interest The authors declare no competing interests.

Publisher's note Springer Nature remains neutral with regard to jurisdictional claims in published maps and institutional affiliations.

\section{References}

1. Gerhardt K, Abrams R. Fetal exposures to sound and vibroacoustic stimulation. J Perinatol. 2000;20:S21-30.

2. Jardri R, Houfflin-Debarge V, Delion P, Pruvo J, Thomas P, Pins D. Assessing fetal response to maternal speech using a noninvasive functional brain imaging technique. Int J Dev Neurosci. 2012;30:159-61.

3. Caskey M, Stephens B, Tucker R, Vohr B. Importance of parent talk on the development of preterm infant vocalizations. Pediatrics. 2011;128:910-6.

4. Newman L. Social and sensory environment of low birth weight infants in a special care nursery: an anthropological investigation. J Nerv Ment Dis. 1981;169:448-55.

5. Barre N, Morgan A, Doyle LW, Anderson PJ. Language abilities in children who were very preterm and/or very low birth weight: a meta-analysis. J Pediatrics. 2011;158:766-74.e1.

6. Foster-Cohen S, Edgin JO, Champion PR, Woodward LJ. Early delayed language development in very preterm infants: evidence from the MacArthur-Bates CDI. J Child Lang. 2007;34:655-75.

7. Bhutta AT, Cleves MA, Casey PH, Cradock MM, Anand KJS. Cognitive and behavioral outcomes of school-aged children who were born preterm. JAMA. 2022;288:728-37.

8. Fifer W, Moon C. The role of mother's voice in the organization of brain function in the newborn. Acta Paediatr Suppl. 1994;397:86-93.

9. deRegnier RA, Wewerka S, Georgieff MK, Mattia F, Nelson CA. Influences of postconceptional age and postnatal experience on the development of auditory recognition memory in the newborn infant. Dev Psychobiol. 2002;41:216-25.

10. Picciolini O, Porro M, Meazza A, Gianni ML, Rivoli C, Lucco G, et al. Early exposure to maternal voice: effects on preterm infants development. Early Hum Dev. 2014;90:287-92.

11. Caskey M, Stephens B, Tucker R, Vohr B. Adult talk in the NICU with preterm infants and developmental outcomes. Pediatrics. 2014;133:e578-84.

12. Hart B, Risley TR. Meaningful differences in the everyday experience of young American children. Baltimore, MD: P.H. Brookes; 1995.

13. Ramirez-Esparza N, Garcia-Sierra A, Kuhl PK. Look who's talking: speech style and social context in language input to infants are linked to concurrent and future speech development. Dev Sci. 2014;17:880-91.
14. Ramirez-Esparza N, Garcia-Sierra A, Kuhl PK. Look who's talking NOW! Parentese speech, social context, and language development across time. Front Psychol. 2017;8:1008.

15. Lester BM, Hawes K, Abar B, Sullivan M, Miller R, Bigsby R, et al. Single-family room care and neurobehavioral and medical outcomes in preterm infants. Pediatrics. 2014;134:754-60.

16. Vohr B, McGowan E, McKinley L, Tucker R, Keszler L, Alksninis B. Differential effects of the single-family room neonatal intensive care unit on 18- to 24-month Bayley scores of preterm infants. J Pediatr. 2017;185:42-48.e1.

17. Lester BM, Salisbury AL, Hawes K, Dansereau LM, Bigsby R, Laptook A, et al. 18-Month follow-up of infants cared for in a single-family room neonatal intensive care unit. J Pediatr. 2016; 177:84-9.

18. Pineda R, Bender J, Hall B, Shabosky L, Annecca A, Smith J. Parent participation in the neonatal intensive care unit: Predictors and relationships to neurobehavior and developmental outcomes. Early Hum Dev. 2018;117:32-8.

19. Lewis TP, Andrews KG, Shenberger E, Betancourt TS, Fink G, Pereira S, et al. Caregiving can be costly: a qualitative study of barriers and facilitators to conducting kangaroo mother care in a US tertiary hospital neonatal intensive care unit. BMC Pregnancy Childbirth. 2019;19:227.

20. Fritsch-deBruyn R, Capalbo M, Rea A, Siano B. Cuddler Program provides soothing answers. Neonatal Netw. 1990;8:45-49.

21. Gilkerson J, Richards JA. The LENA ${ }^{\mathrm{TM}}$ Natural Language Study. Boulder, CO: LENA ${ }^{\mathrm{TM}}$ Foundation; 2008.

22. Leffel K, Suskind D. Parent-directed approaches to enrich the early language environments of children living in poverty. Semin Speech Lang. 2013;34:267-78.

23. Hoffman L, Hersey A, Tucker R, Vohr B. Randomised control language intervention for infants of adolescent mothers. Acta Paediatr. 2020;109:2604-13.

24. Gilkerson J, Richards JA, Warren SF, Montgomery JK, Greenwood CR, Kimbrough Oller D, et al. Mapping the early language environment using all-day recordings and automated analysis. Am J Speech Lang Pathol. 2017;26:248-65.

25. Gilkerson J, Richards JA, Warren SF, Oller DK, Russo R, Vohr B. Language experience in the second year of life and language outcomes in late childhood. Pediatrics. 2018;142:4.

26. Suskind DL, Leffel KR, Graf E, Hernandez MW, Gunderson EA, Sapolich SG, et al. A parent-directed language intervention for children of low socioeconomic status: a randomized controlled pilot study. J Child Lang. 2016;43:366-406.

27. Carpenter M, Nagell K, Tomasello M. Social cognition, joint attention, and communicative competence from 9 to 15 months of age. Monogr Soc Res Child Dev. 1998;63:1-143. i-vi

28. Landry SH, Smith KE, Swank PR, Guttentag C. A responsive parenting intervention: the optimal timing across early childhood for impacting maternal behaviors and child outcomes. Dev Psychol. 2008;44:1335-53.

29. Mayberry RI, Lock E, Kazmi H. Linguistic ability and early language exposure. Nature. 2002;417:38.

30. Pineda RG, Neil J, Dierker D, Smyser CD, Wallendorf M, Kidokoro $\mathrm{H}$, et al. Alterations in brain structure and neurodevelopmental outcome in preterm infants hospitalized in different neonatal intensive care unit environments. J Pediatr. 2014;164: 52-60.e2.

31. Pineda R, Durant $\mathrm{P}$, Mathur A, Inder $\mathrm{T}$, Wallendorf $\mathrm{M}$, Schlaggar BL. Auditory exposure in the neonatal intensive care unit: room type and other predictors. J Pediatr. 2017;183: 56-66.e3.

32. Pineda RG, Stransky KE, Rogers C, Duncan MH, Smith GC, Neil $\mathrm{J}$, et al. The single-patient room in the NICU: maternal and family effects. J Perinatol. 2012;32:545-51. 
33. Zimmerman FJ, Gilkerson J, Richards JA, Christakis DA, $\mathrm{Xu} \mathrm{D}$, Gray S, et al. Teaching by listening: the importance of adult-child conversations to language development. Pediatrics. 2009;124:342-9.

34. Haider AH, Schneider EB, Sriram N, Scott VK, Swoboda SM, Zogg $\mathrm{CK}$, et al. Unconscious race and class biases among registered nurses: vignette-based study using implicit association testing. J Am Coll Surg. 2015;220:1077-86.e3.

35. Zebib L, Strong B, Moore G, Ruiz G, Rattan R, Zakrison TL. Association of racial and socioeconomic diversity with implicit bias in acute care surgery. JAMA Surg. 2019;154: 459-61. 